\title{
Mechanism of continuous high temperature affecting growth performance, meat quality, and muscle biochemical properties of finishing pigs
}

\author{
Xianyong Ma ${ }^{1,2,3,4,5^{*}}$ D, Li Wang ${ }^{1,2,3,4,5}$, Zibiao Shi ${ }^{1,2,3,4,5}$, Wei Chen ${ }^{1,2,3,4,5}$, Xuefen Yang ${ }^{1,2,3,4,5}$, Youjun Hu $u^{1,2,3,4,5}$ \\ Chuntian Zheng $1,2,3,4,5$ and Zongyong Jiang ${ }^{1,2,3,4,5^{*}}$
}

\begin{abstract}
Background: The mechanism of high ambient temperature affecting meat quality is not clear till now. This study investigated the effect of high ambient temperature on meat quality and nutrition metabolism in finishing pigs.

Methods: All pigs received the same corn-soybean meal diet. A total of 24 Landrace $\times$ Large White pigs (60 kg BW, all were female) were assigned to three groups: $22 \mathrm{AL}$ (fed ad libitum at $22^{\circ} \mathrm{C}$ ), $35 \mathrm{AL}$ (ad libitum fed at $35^{\circ} \mathrm{C}$ ), and $22 \mathrm{PF}$ (at $22^{\circ} \mathrm{C}$, but fed the amount consumed by pigs raised at $35^{\circ} \mathrm{C}$ ) and the experiment lasted for 30 days.

Results: Feed intake, weight gain, and intramuscular fat (IMF) content of pigs were reduced, both directly by high temperature and indirectly through reduced feed intake. Transcriptome analysis of longissimus dorsi (LM) showed that downregulated genes caused by feed restriction were mainly involved in muscle development and energy metabolism; and upregulated genes were mainly involved in response to nutrient metabolism or extracellular stimulus. Apart from the direct effects of feed restriction, high temperature negatively affected the muscle structure and development, energy, or catabolic metabolism, and upregulated genes were mainly involved in DNA or protein damage or recombination, cell cycle process or biogenesis, stress response, or immune response.

Conclusion: Both high temperature and reduced feed intake affected growth performance and meat quality. Apart from the effects of reducing feed intake, high temperature per se negatively downregulated cell cycle and upregulated heat stress response. High temperature also decreased the energy or catabolic metabolism level through PPAR signaling pathway.
\end{abstract}

Keywords: Growth performance, High ambient temperature, Meat quality, mRNA array, Restricted feed intake

\section{Introduction}

Continuous high temperature, especially in summer in tropical or subtropical countries, is an unfavorable factor in swine production. Persistent exposure to high temperature decreases feed intake [1], growth performance [2], and meat quality [3, 4]. For example, high temperature reduced intramuscular fat (IMF) deposition $[5,6]$ and changed the $\mathrm{pH}$ value of the meat $[3,7]$. These alterations were traditionally believed to result from the

\footnotetext{
* Correspondence: lilymxy80@sohu.com; jiangz28@qq.com

${ }^{1}$ Institute of Animal Science, Guangdong Academy of Agricultural Sciences,

Guangzhou 510640, People's Republic of China

Full list of author information is available at the end of the article
}

decreased feed intake, but more recent studies have shown that heat stress per se also reduced metabolic rates and altered post-absorptive metabolism, regardless of decreased feed intake $[8,9]$. Heat stress also changed expression of some genes related to oxidative metabolism, through adaptive physiological mechanisms, to reduce thermogenesis [7, 10]. Although inferior meat quality induced by heat stress has been intensively studied, the molecular mechanisms underlying the pathophysiological changes remain to be defined. As heat stress does decrease feed intake, it remains unclear what changes are dependent or independent low nutrient availability. Gene expression profiles of longissimus

(c) The Author(s). 2019 Open Access This article is distributed under the terms of the Creative Commons Attribution 4.0 International License (http://creativecommons.org/licenses/by/4.0/), which permits unrestricted use, distribution, and 
muscle (LM) have been used here to further examine how heat stress affects meat quality and the extent to which it is dependent on reduced feed intake.

\section{Materials and methods}

\section{Animals and diets}

A total of 24 Landrace $\times$ Large White pigs $(60 \mathrm{~kg} \mathrm{BW})$ were assigned randomly to three groups with eight pigs per group. Pigs were housed individually in wire cages $(139 \times 67 \times 115 \mathrm{~cm})$ in one of three temperaturecontrolled rooms at the Institute of Animal Science, Guangdong Academy of Agricultural Sciences. After adaption for 1 week, pigs were treated as follows: a control group of pigs had ad libitum access to feed at $22{ }^{\circ} \mathrm{C}$ (RT) (22AL); the heat-stressed group had ad libitum access to feed at $35{ }^{\circ} \mathrm{C}$ (35AL); and pair-fed pigs at $22{ }^{\circ} \mathrm{C}$ $(22 \mathrm{PF})$ were fed the amount consumed by pigs raised at $35{ }^{\circ} \mathrm{C}$. All pigs were fed twice daily with a typical cornsoybean meal-based diet for finishing pigs (the diet formula is available as Additional file 1: Table S1). The temperature in one room was increased from 22 to $35{ }^{\circ} \mathrm{C}$ within approximately $2 \mathrm{~h}$ and then remained at $35{ }^{\circ} \mathrm{C}$ for the $30-\mathrm{d}$ experimental period; other rooms were maintained at $22{ }^{\circ} \mathrm{C}$. Water was available ad libitum for all pigs.

\section{Feeding, slaughter procedure, and sample collection}

All aspects of the experiment including transport and slaughtering procedures were carried out in accordance with the Chinese guidelines for the use of experimental animals and animal welfare [11] and approved by the Animal Experimental Committee of the Institute of Animal Science, Guangdong Academy of Agricultural Sciences. Pigs were weighed at the beginning and feed intakes were recorded to determine average daily gain (ADG), average daily feed intake (ADFI), and feed to gain ratio (F:G). At the end of the experiment, all pigs were fasted for $14 \mathrm{~h}$, and then slaughtered; the whole LM samples were taken immediately after slaughtered for testing meat quality and parts samples at the last thoracic vertebra were collected and stored at $-80{ }^{\circ} \mathrm{C}$ for subsequent analyses.

\section{Meat quality measurements}

The $\mathrm{pH}$ of muscle samples was measured at $45 \mathrm{~min}$, $24 \mathrm{~h}$, and $48 \mathrm{~h}$ postmortem using a $\mathrm{pH}$ meter (HI 8242C, Beijing Hanna Instruments Science \& Technology, Beijing, China). Meat color CIE LAB values ( $L^{*}$, lightness; $a$, redness; $b$, yellowness) were determined on the transverse surface of the LM after it was cut and let to bloom for $45 \mathrm{~min}$ at the same times postmortem using a colorimeter (CR-410, Minolta, Suita-shi, Osaka, Japan), as described by Mason et al. [12]. Shear force was measured using an Instron Universal Mechanical
Machine (Instron model 4411; Instron, Canton, MA, USA) and drip loss was measured by weight loss over $24 \mathrm{~h}$ at $4{ }^{\circ} \mathrm{C}$ in a plastic bag, also as described by Mason et al. [12]. The IMF content was measured by petroleum ether extraction of powdered, lyophilized muscle using the Soxtec 2055 fat extraction system (Foss Tecator AB, Höganäs, Sweden), according to the Association of Official Analytical Chemists method [13].

\section{RNA extraction and target labeling}

Total RNA was isolated from LM using the TRIzol reagent (Invitrogen, Carlsbad, CA, USA) and purified using a QIAGEN RNeasy Mini Kit (QIAGEN, Chatsworth, CA, USA) according the manufacturer's instructions. The RNA quality was checked with a spectrophotometer (ND1000, Nano-Drop Technologies, Wilmington, DE, USA). Each RNA sample was annealed with a primer containing a poly-dT and a T7 polymerase promoter. Reverse transcriptase produced primary and secondary cDNA strands. T7 RNA polymerase was then used to create cRNA from the double-stranded cDNA by incorporating cyanine-3labeled cytidine 3-CTP according to the labeling kit recommendations (Agilent Technologies, Santa Clara, CA, USA). The quality of the labeled cRNA was again verified.

\section{Hybridization, scanning, and feature extraction}

A total of 24 pigs were used and four cRNA pools of two pigs per treatment was hybridized to 12 microarrays $(4 \times 3$ treatments) using a Gene Expression Hybridization Kit (Agilent) at $60{ }^{\circ} \mathrm{C}$ for $17 \mathrm{~h}$ using whole pig genome arrays (Pig 4x44K Gene Expression Microarrays v2, Agilent). The arrays were washed, stabilized, and dehydrated, as recommended, then examined on a G2565BA microarray scanner (Agilent) and the data were compiled using feature extraction software $(\mathrm{FE})$.

\section{Data analysis of the mRNA microarrays}

Array normalizations and error detection were carried out using Silicon Genetics' GeneSpring GX v11.5.1 (Agilent) via the enhanced FE import preprocessor, then was normalized using the supplied algorithms. A final quality control filter was applied to eliminate transcripts with excessive biological variability then GeneSpring was used to reveal genes significantly differing in expression among the 3 treatments. Differentially expressed genes with statistical significance between pairs of treatments were those passing Volcano Plot filtering (Fold Change $\geq 2.0, P$ value $\leq 0.05$ ).

\section{Real-time PCR analysis}

Total RNA, extracted as described above, was used to prepare cDNA (four pools of two pigs per treatment) with PrimeScript RT reagent kits (Takara, Ostu, Japan) according to the manufacturer's instruction. Real-time PCR was carried out on a CFX connect Real-Time 
System (Bio-Rad, Hercules, CA) using the iTaq Universal SYBR Green SuperMix (Bio-Rad Laboratories) with gene-specific primers. The primer sequences (listed in Table 4) were designed using Primer Express 5. The PCR protocol was as follows: denaturation at $95{ }^{\circ} \mathrm{C}$ for $30 \mathrm{~s}$, followed by 40 cycles of $95^{\circ} \mathrm{C}$ for $20 \mathrm{~s}$ and $60{ }^{\circ} \mathrm{C}$ for $20 \mathrm{~s}$, then $72{ }^{\circ} \mathrm{C}$ for $30 \mathrm{~s}$. The relative abundance of transcripts was expressed as $2^{-\Delta \Delta \mathrm{Ct}}$, where the $\mathrm{Ct}$ (threshold cycle) value for each reaction was used to calculate gene expression, and then further normalized to abundance in the 22AL control animals, given a value of 1 .

\section{Western blotting}

Pools (four pools of two pigs per treatment) of muscle proteins $(40 \mu \mathrm{g}$, one for each treatment) were separated by SDS-PAGE and proteins were electro-transferred to PVDF membranes at $250 \mathrm{~mA}$ for $90 \mathrm{~min}$, as described by $\mathrm{Ma}$ et al. [14]. Membranes were blocked overnight at $4{ }^{\circ} \mathrm{C}$ with $5 \%$ non-fat milk in TBST $(10 \mathrm{mmol} / \mathrm{L}$ Tris- $\mathrm{HCl}, \mathrm{pH}$ 8.0, $150 \mathrm{mmol} / \mathrm{L} \mathrm{NaCl}, 0.1 \%$ Tween 20 ). All primary antibodies were raised in rabbits and were suitable for detecting specific porcine proteins: DECR1(sc-393473, Santa Cruz Biotechnology, Dallas, TX), FABP3 (orb156814, Biorbyt, Berkeley, CA), HSPA1L (bs-18079R, Bioss, Columbia, TN), LPIN1 (sc-50050, Santa Cruz), PEKM (sc-31712, Santa Cruz), TNNI1 (orb106871, Biorbyt), TNNT3 (BWBMS201C, Genway Biotech, San Diego, CA), PPARGC-1 (bs-7535R, Bioss), MSTN (ab98337, Abcam), FASN (ab128856, Abcam), PCK1 (ab87340, Abcam), and GAPDH (sc-20357, Santa Cruz). Each was used at 1:250 diluted in blocking buffer for $2 \mathrm{~h}$ at room temperature. Membranes were washed three times, each for $10 \mathrm{~min}$, with $10 \mathrm{~mL}$ TBST then incubated for $1 \mathrm{~h}$ in blocking buffer containing horseradish peroxidase-labeled (HRP) antirabbit secondary antibody (ABCAM Biotechnology, Cambridge, UK) diluted 1:5000. After three 10-min washes, immunoreactive proteins were visualized using a chemiluminescent HRP substrate (Millipore, Billerica, MA) and a Versa Doc imaging system (Bio-Rad). The band densities were calculated by Quantity One software (Bio-Rad) and compared to the density of GADPH. The Western blot analyses were performed in triplicate and data were analyzed with IMAGE J 1.49 software (NIH, Bethesda, MD).

\section{Statistical analysis}

The effect of treatment was examined by one-way ANOVA and, where appropriate, means were compared using Fisher's least significant difference (LSD) post-hoc tests (SPSS V22). Differences were considered to be significant at $P<0.05$. Microarray analyses were conducted using GeneSpring GX v11.5.1, via the enhanced FE import preprocessor, then normalized using the supplied algorithms. Significant GO ID pathways were selected by adjusted $P$ value $<0.05$.

\section{Results}

\section{Growth performance and meat quality}

The performance and meat quality data are summarized in Table 1. The final BW, ADFI, and ADG of the control pigs (22AL) were much higher than those in the heatstressed (35AL) or pair-fed pigs $(22 \mathrm{PF})(P<0.05)$, but the backfat thickness of the first rib in the control was lower than that in the heat-stressed or pair-fed pigs $(P<0.05)$, the latter having the lowest F:G ratio. There were no differences on loin eye area and leaf fat weight among three groups $(P>0.05)$. The $\mathrm{pH}$ value of $\mathrm{LM}$ in $35 \mathrm{AL}$ pigs was higher than that in the PF pigs at 45 min postmortem $(P<0.05)$, was higher than that of other two treatments at $24 \mathrm{~h}(P<0.05)$, and exceeded that of the $22 \mathrm{AL}$ pigs at $48 \mathrm{~h}$ $(P<0.05)$. There were no differences in drip loss at $24 \mathrm{~h}$ or $48 \mathrm{~h}$ postmortem, nor in meat color $\left(a, b\right.$, and $L^{*}$ value) except for $L^{*}$ at 45 -min postmortem being lowest in the 22AL controls $(P<0.05)$. Both high temperature and feed restriction decreased IMF content in LM $(P<0.05)$. The shear force value in $22 \mathrm{PF}$ pigs was greatest in $22 \mathrm{PF}$ pigs $(P<0.05)$, without any difference between $35 \mathrm{AL}$ and 22AL pigs.

mRNA expression profiling and bioinformatics analysis More than 22,100 pig probes were detectable and the 22AL, 22PF, and 35AL treatments were compared and significant changes $(\geq 2.0$-fold, $P \leq 0.05)$ are described here. Compared with the $22 \mathrm{AL}$ controls, 660 genes were upregulated and 1159 genes downregulated in the 35AL pigs while 162 genes were upregulated and 191 genes downregulated in the pair-fed, $22 \mathrm{PF}$ pigs. To assess effects of high temperature distinct from the reduced level of intake, the comparison between 22PF and 22AL pigs identified 466 upregulated and 688 downregulated genes (Fig. 1). From these differentially expressed genes, parts of representative genes related to lipid metabolism, glucose metabolism, muscle structure development, and cellular response to stress were selected and listed in Table 2. Compared with the control, most of the lipid metabolic process related genes in 35AL group were downregulated such as ACSL1(acyl-CoA synthetase long-chain family member 1), ITGAV (integrin, alpha V), FABP3 (fatty acid binding protein 3), DLD (dihydrolipoamide dehydrogenase), CPT1B (carnitine palmitoyltransferase 1B), LPL (lipoprotein lipase), SCD (stearoylCoA desaturase), DECR1 (2,4-dienoyl CoA reductase 1, mitochondrial), ACADL (acyl-CoA dehydrogenase, long chain), ACADM (acyl-CoA dehydrogenase), ACOX1 (acyl-CoA oxidase 1), CYP2E1 (cytochrome P450, family 2, subfamily E, polypeptide 1), ATP5B (ATPase 5B), CPT1A (carnitine palmitoyltransferase 1A), LPINI (lipin 1), while FASN (fatty acid synthase), CYP2E1, and PPARGC-1 (peroxisome proliferator activated receptor gamma, coactivator 1 alpha) were upregulated; DECR1, CPT1A, and 
Table 1 Effect of high temperature and feed restriction on growth performance and meat quality of finishing pigs

\begin{tabular}{|c|c|c|c|c|c|c|}
\hline \multirow{3}{*}{\multicolumn{2}{|c|}{ Variable }} & \multicolumn{3}{|l|}{ Treatment } & \multirow[t]{3}{*}{ S.E.M } & \multirow[t]{3}{*}{$P$ value } \\
\hline & & \multirow{2}{*}{$\begin{array}{l}22 \mathrm{AL} \\
\left(22^{\circ} \mathrm{C}, \text { ad lib) }\right.\end{array}$} & \multirow{2}{*}{$\begin{array}{l}\text { 22PF } \\
\left(22^{\circ} \mathrm{C} \text {, pair-fed }\right)\end{array}$} & \multirow{2}{*}{$\begin{array}{l}35 \mathrm{AL} \\
\left(35^{\circ} \mathrm{C} \text {, ad lib) }\right.\end{array}$} & & \\
\hline & & & & & & \\
\hline \multicolumn{2}{|l|}{ Initial BW, kg } & 77.75 & 77.62 & 77.80 & 0.416 & 0.630 \\
\hline \multicolumn{2}{|l|}{ Final BW, kg } & 103.85 & 86.02 & 87.70 & 10.12 & $<0.001$ \\
\hline \multicolumn{2}{|l|}{ ADG, kg/day } & $0.87^{\mathrm{a}}$ & $0.28^{\mathrm{b}}$ & $0.33^{\mathrm{b}}$ & 0.061 & $<0.001$ \\
\hline \multicolumn{2}{|l|}{ ADFl, kg/day } & $3.02^{\mathrm{a}}$ & $1.68^{\mathrm{b}}$ & $1.51^{\mathrm{b}}$ & 0.146 & $<0.001$ \\
\hline \multicolumn{2}{|l|}{ G:F } & $0.29^{\mathrm{b}}$ & $0.17^{\mathrm{a}}$ & $0.22^{\mathrm{b}}$ & 0.015 & 0.001 \\
\hline \multirow{3}{*}{\multicolumn{2}{|c|}{ Backfat first rib, mm Thickness tenth rib, mm Last rib, mm }} & $33.67^{\mathrm{a}}$ & $39.09^{b}$ & $42.77^{b}$ & 0.862 & 0.043 \\
\hline & & 21.48 & 22.04 & 22.27 & 0.974 & 0.715 \\
\hline & & 14.05 & 17.63 & 18.85 & 0.315 & 0.057 \\
\hline \multicolumn{2}{|c|}{ Loin eye area, $\mathrm{mm}^{2}$} & 4766 & 4431 & 4355 & 0.507 & 0.431 \\
\hline \multicolumn{2}{|c|}{ Leaf fat weight, $\mathrm{kg}$} & 0.525 & 0.534 & 0.586 & 0.442 & 0.373 \\
\hline \multirow[t]{3}{*}{$\mathrm{pH}$} & $45 \mathrm{~min}$ & $6.10^{\mathrm{b}}$ & $6.15^{\mathrm{ab}}$ & $6.20^{\mathrm{a}}$ & 0.04 & 0.113 \\
\hline & $24 \mathrm{~h}$ & $5.48^{\mathrm{b}}$ & $5.48^{b}$ & $5.57^{\mathrm{a}}$ & 0.014 & 0.002 \\
\hline & $48 \mathrm{~h}$ & $5.52^{\mathrm{b}}$ & $5.55^{\mathrm{ab}}$ & $5.64^{\mathrm{a}}$ & 0.022 & 0.053 \\
\hline \multirow[t]{2}{*}{ Drip loss,\% } & $24 \mathrm{~h}$ & 2 & 2 & 2.05 & 0.095 & 0.977 \\
\hline & $48 \mathrm{~h}$ & 2.61 & 2.48 & 2.59 & 0.101 & 0.872 \\
\hline \multirow[t]{3}{*}{$L^{*}$} & $45 \mathrm{~min}$ & $45.25^{b}$ & $46.58^{\mathrm{a}}$ & $47.45^{\mathrm{a}}$ & 0.303 & $<0.001$ \\
\hline & $24 \mathrm{~h}$ & 57.87 & 58.19 & 58.11 & 0.415 & 0.926 \\
\hline & $48 \mathrm{~h}$ & 57.75 & 58.18 & 58.87 & 0.386 & 0.082 \\
\hline \multirow[t]{3}{*}{$a$} & $45 \mathrm{~min}$ & 15.84 & 15.58 & 15.81 & 0.203 & 0.864 \\
\hline & $24 \mathrm{~h}$ & 15.39 & 14.67 & 14.42 & 0.147 & 0.511 \\
\hline & $48 \mathrm{~h}$ & 15.12 & 15.55 & 15.06 & 0.210 & 0.612 \\
\hline \multirow[t]{3}{*}{$b$} & $45 \mathrm{~min}$ & 2.31 & 2.61 & 2.59 & 0.112 & 0.503 \\
\hline & $24 \mathrm{~h}$ & 3.98 & 3.4 & 3.62 & 0.142 & 0.269 \\
\hline & $48 \mathrm{~h}$ & 3.11 & 3.16 & 3.23 & 0.167 & 0.96 \\
\hline \multicolumn{2}{|l|}{$\mathrm{IMF}, \%$} & $4.77^{\mathrm{a}}$ & $3.03^{b}$ & $2.89^{b}$ & 0.351 & 0.05 \\
\hline \multicolumn{2}{|c|}{ Shear force, $N$} & $41.51^{b}$ & $49.01^{\mathrm{a}}$ & $43.15^{\mathrm{b}}$ & 1.127 & 0.038 \\
\hline \multicolumn{2}{|c|}{ Glycogen content, mg/g } & $2.15^{\mathrm{a}}$ & $1.38^{b}$ & $1.19^{\mathrm{b}}$ & 0.681 & 0.046 \\
\hline
\end{tabular}

Data are means with s.e.m., $n=8$

$\mathrm{a}, \mathrm{b}$, Within a row, means with a common superscript do not differ $(P>0.05)$

$A D G$ average daily gain, $A D F I$ average daily feed intake, $F: G$, feed gain ratio, $I M F$ intramuscular fat, $L^{*}$ lightness, $a$ redness, $b$ yellowness

PPARGC-1 in 22PF group were downregulated. Compared with 22PF group, ITGAV, DLD, DECR1, ACADM, ATP5B, and APOC3 (apolipoprotein C-III) were downregulated. Glucose metabolic process related genes (UGP2(UDP-glucose pyrophosphorylase 2), GPI (glucose-6-phosphate isomerase), GPD1 (glycerol-3-phosphate dehydrogenase 1), PFKM (phosphofructokinase), TPI1 (triosephosphate isomerase 1), PKM2 (Pyruvate kinase isozyme type M2), PGM1 (Phosphoglucomutase 1)) expression in $35 \mathrm{AL}$ group were lower than those in 22AL and 22PF group. Compared with control, PCK1 was upregulated in 35AL and 22PF group. All the genes related with muscle structure development listed in Table 2 were downregulated in 35AL group and most of them were downregulated in 22PF group compared with the control. Cellular response to stress-related genes such as GTF2H4 (general transcription factor IIH subunit 4), ERCC1 (excision repair cross-complementing rodent repair complementation group 1), HSPA1L (heat shock $70 \mathrm{kDa}$ protein 1-like), MLH1 (mutL homolog 1), GADD45A (growth arrest and DNA- damage-inducible, alpha), CDKN1A (cyclin-dependent kinase inhibitor 1A), MAPK14 (mitogen-activated protein kinase 14), and TICAM2 (toll-like receptor adaptor molecule 2) were upregulated in 35AL group and some of them were upregulated in $22 \mathrm{PF}$ group compared with the control. Cellular response to hormone stimulus related genes such as NR3C1, GHR, ACVR1, ADRB2, IFNGR2, FOLR2, and ADIPOR1 in 35AL group was downregulated and some of them in 22PF group was downregulated compared with the control. 


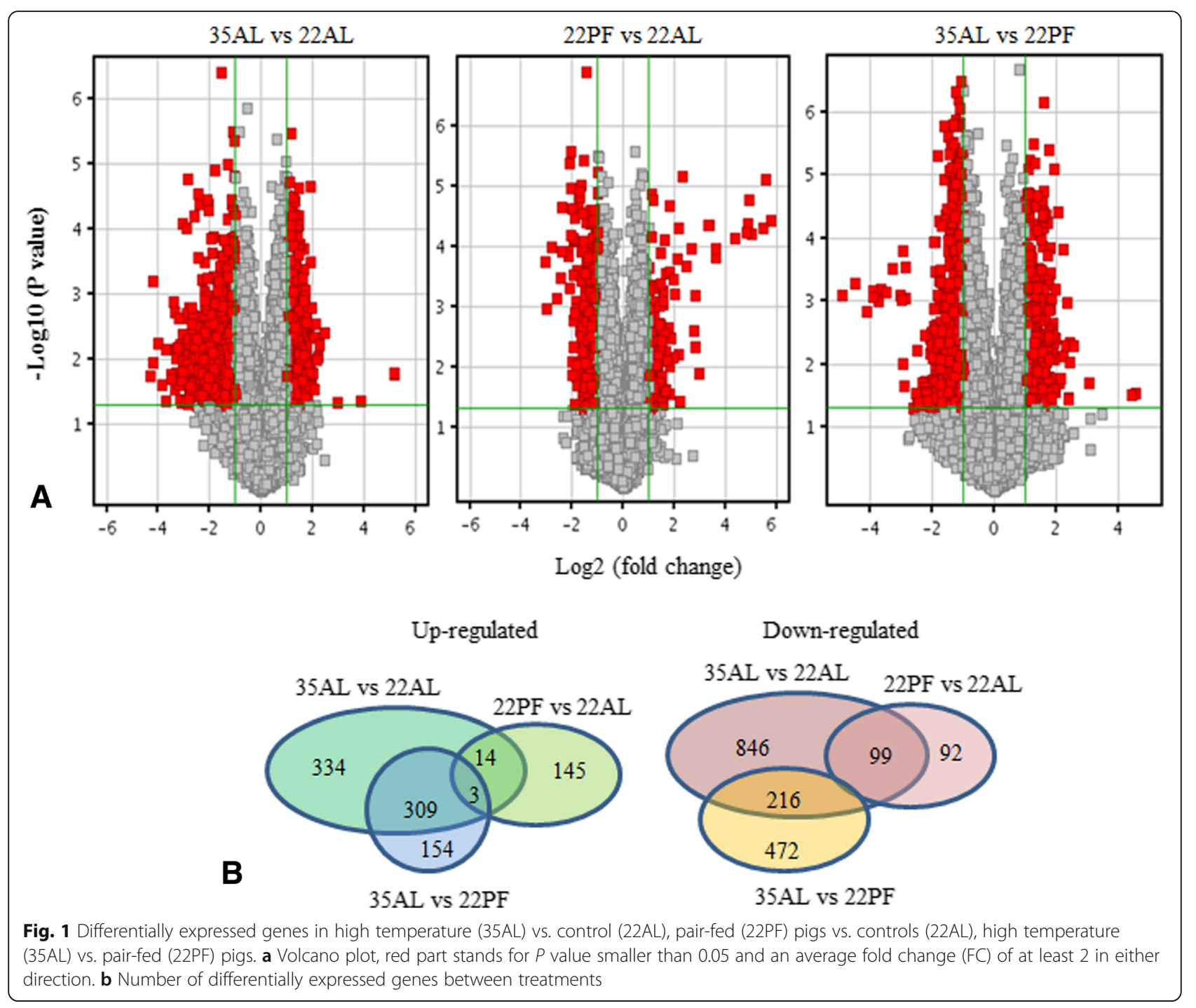

To further characterize the types of genes altered in response to heat stress or reduced feed intake, the differentially expressed genes were classified according to gene ontology (GO) slim terms. GO slim ranks high level terms from each of the three major gene ontologies: biological process, cellular component, and molecular function. Biological process analysis results are listed in Additional file 2: Tables S2, Additional file 3: Table S3, and Additional file 4: Table S4. Biological process analysis found that the differentially expressed genes were predominantly related to energy metabolism, muscle tissue development, catabolic process, or stress. Compared with the 22AL pigs, the downregulated genes in the 35AL pigs are mainly involved in muscle development or cell growth (GO:0060537, GO:0045927), actin cytoskeleton organization (GO:0030036), cellular ketone or oxoacid metabolic process (GO:0042180, GO:0043436), actin filamentbased process or actomyosin structure organization (GO: 0030029, GO:0031032), cellular component organization
(GO:0016043), and catabolic process (GO:0009056); the upregulated genes are mainly involved in RNA processing or translation(GO:0006364,GO:0006412), DNA damage stimulus or DNA recombination (GO:0006974, GO:0016444), cell cycle arrest (GO:0022402), and amino acid metabolism (GO: 0043038) (Additional file 2: Table S2). Assessing reduced feed intake, compared with 22AL controls, the downregulated genes in $22 \mathrm{PF}$ pigs are mainly involved in muscle contraction or morphogenesis (GO:0006936, GO:0060415), cellular component biogenesis or organization (GO:0044085, GO: 0016043,GO:0071840), and muscle cell differentiation (GO: 0051146); the upregulated genes are mainly involved in response to nutrient levels (GO:0031667), response to extracellular stimulus (GO:0009991), lipid, steroid, or acetyl-CoA metabolic process (GO:0006629, GO:0008202, GO:0006084) (Additional file 3: Table S3). Assessing direct effects of heat stress, compared with 22PF pigs, the downregulated genes in the 35AL pigs are involved in muscle development (GO: 0060537, GO:0061061), growth rate (GO:0040009, GO: 
Table 2 Differentially expressed genes related to energy metabolism, muscle structure, and stress response

\begin{tabular}{|c|c|c|c|c|}
\hline \multirow[t]{2}{*}{ Gene $^{a}$} & \multirow[t]{2}{*}{ Description } & \multicolumn{3}{|l|}{ Fold change $^{\mathrm{b}}$} \\
\hline & & $35 \mathrm{AL}$ vs. $22 \mathrm{AL}$ & 22PF vs. $22 \mathrm{AL}$ & $35 \mathrm{AL}$ vs. $22 \mathrm{PF}$ \\
\hline \multicolumn{5}{|c|}{ Lipid metabolic process } \\
\hline ACSL1 & Acyl-CoA synthetase long-chain family member 1 & 0.22 & & 0.45 \\
\hline ITGAV & Integrin, alpha V & 0.25 & & \\
\hline CD36 & CD36 molecule & 0.28 & & \\
\hline FABP3 & Fatty acid binding protein 3 & 0.42 & 0.46 & \\
\hline$D L D$ & Sus scrofa dihydrolipoamide dehydrogenase & 0.22 & & 0.29 \\
\hline CPT1B & Carnitine palmitoyltransferase $1 \mathrm{~B}$ & 0.48 & & \\
\hline$L P L$ & Lipoprotein lipase & 0.35 & & \\
\hline$S C D$ & Stearoyl-CoA desaturase & 0.18 & & \\
\hline DECR1 & 2,4-Dienoyl CoA reductase 1, mitochondria & 0.24 & 0.50 & 0.50 \\
\hline$A C A D L$ & Acyl-CoA dehydrogenase, long chain & 0.47 & 0.39 & \\
\hline ACADM & Acyl-CoA dehydrogenase & 0.39 & & 0.46 \\
\hline ACOX1 & Acyl-CoA oxidase 1, palmitoyl & 0.44 & & \\
\hline CYP2E1 & Cytochrome P450, family 2, subfamily E, polypeptide 1 & 6.22 & & 3.79 \\
\hline ATP5B & ATP synthase, $\mathrm{H}+$ transporting, mitochondrial F1 complex & 0.21 & & 0.41 \\
\hline FASN & Sus scrofa fatty acid synthase & 2.42 & & \\
\hline APOC3 & Sus scrofa apolipoprotein C-III & & 4.99 & 0.29 \\
\hline CPT1A & Sus scrofa carnitine palmitoyltransferase $1 \mathrm{~A}$ & & 0.45 & \\
\hline LPINI & Sus scrofa lipin 1 mRNA & 0.35 & 0.38 & 0.72 \\
\hline PPARGC-1 & $\begin{array}{l}\text { Sus scrofa peroxisome proliferator activated receptor gamma, coactivator } 1 \text { alpha } \\
\text { (PPARGC-1) }\end{array}$ & 2.37 & & \\
\hline \multicolumn{5}{|c|}{ Glucose metabolic process } \\
\hline UGP2 & UDP-glucose pyrophosphorylase 2 & 0.16 & & 0.40 \\
\hline GPI & Glucose-6-phosphate isomerase & 0.20 & & 0.34 \\
\hline GPD1 & Glycerol-3-phosphate dehydrogenase 1 & 0.38 & & 0.44 \\
\hline PFKM & Phosphofructokinase, muscle & 0.36 & & 0.45 \\
\hline TPI1 & Triosephosphate isomerase 1 & 0.15 & & 0.23 \\
\hline PKM2 & Pyruvate kinase, muscle & 0.14 & & 0.23 \\
\hline PGM1 & Phosphoglucomutase & 0.35 & & 0.33 \\
\hline PCK1 & Sus scrofa phosphoenolpyruvate carboxykinase 1 & 2.42 & 2.42 & \\
\hline \multicolumn{5}{|c|}{ Muscle structure development } \\
\hline $\mathrm{SHOC2}$ & Soc-2 suppressor of clear homolog & 0.32 & & 0.45 \\
\hline CASQ1 & Calsequestrin 1 (fast-twitch, skeletal muscle) & 0.46 & & 0.46 \\
\hline MYH4 & Myosin, heavy chain 4, skeletal muscle & 0.29 & & 0.43 \\
\hline ACTA1 & Actin, alpha 1, skeletal muscle & 0.32 & & 0.36 \\
\hline ACTA2 & Actin, alpha 2, smooth muscle, & 0.39 & 0.40 & \\
\hline ACTC1 & Actin, alpha, cardiac muscle 1 & 0.435 & 0.26 & \\
\hline BIN1 & Bridging integrator 1 & 0.17 & & 0.16 \\
\hline$H M G B 1$ & High mobility group box 1 & 0.45 & & 0.34 \\
\hline SGCA & Sarcoglycan, alpha & 0.25 & & 0.40 \\
\hline ITGB1 & Integrin, beta 1 & 0.18 & & 0.27 \\
\hline CTNNB1 & Catenin (cadherin-associated protein), beta 1 & 0.38 & & 0.49 \\
\hline MSTN & Myostatin & 0.41 & 1.14 & 0.36 \\
\hline
\end{tabular}


Table 2 Differentially expressed genes related to energy metabolism, muscle structure, and stress response (Continued)

\begin{tabular}{|c|c|c|c|c|}
\hline \multirow[t]{2}{*}{ Gene $^{a}$} & \multirow[t]{2}{*}{ Description } & \multicolumn{3}{|l|}{ Fold change $^{b}$} \\
\hline & & $35 \mathrm{AL}$ vs. $22 \mathrm{AL}$ & 22PF vs. 22AL & $35 \mathrm{AL}$ vs. $22 \mathrm{PF}$ \\
\hline MYO1B & Myosin IB & 0.349 & 0.42 & \\
\hline РРРЗСВ & Protein phosphatase 3 , catalytic subunit, beta isozyme & 0.18 & & 0.28 \\
\hline CAV2 & Caveolin 2 & 0.25 & & 0.45 \\
\hline TPM2 & Tropomyosin 2 (beta) & 0.33 & & 0.36 \\
\hline TNNT3 & Troponin T type 3 (skeletal, fast) & 0.39 & & 0.45 \\
\hline TNNI1 & Troponin I type 1 (skeletal, slow) & 0.37 & & \\
\hline LMNA & Prelamin-A/C & 0.27 & & 0.44 \\
\hline MYOT & Sus scrofa myotilin & 0.40 & 0.44 & \\
\hline TPM3 & Sus scrofa tropomyosin 3 & 0.41 & & \\
\hline TNNI3 & Troponin I type 3 & 0.39 & 0.42 & 0.45 \\
\hline \multicolumn{5}{|c|}{ Cellular response to stress } \\
\hline GTF2H4 & General transcription factor IIH subunit 4 & 2.13 & & \\
\hline ERCC1 & Excision repair cross-complementing rodent repair complementation group 1 & 2.06 & & \\
\hline HSPA1L & Heat shock $70 \mathrm{kDa}$ protein 1 -like & 2.20 & & 2.64 \\
\hline MLH1 & mutL homolog 1 & 2.09 & & \\
\hline GADD45A & Growth arrest and DNA-damage-inducible, alpha & 2.04 & & \\
\hline CDKN1A & Cyclin-dependent kinase inhibitor $1 \mathrm{~A}$ & & & 3.78 \\
\hline MB & Sus scrofa myoglobin (MB) & 0.12 & & 0.25 \\
\hline CXCL10 & Chemokine (C-X-C motif) ligand 10 & & & 2.58 \\
\hline MAPK14 & Mitogen-activated protein kinase 14 & 3.02 & & 2.11 \\
\hline TICAM2 & Toll-like receptor adaptor molecule 2 & 3.35 & & 2.02 \\
\hline \multicolumn{5}{|c|}{ Cellular response to hormone stimulus } \\
\hline $\mathrm{NR3C1}$ & Nuclear receptor subfamily 3 , group C, member 1 & 0.48 & & \\
\hline GHR & Growth hormone receptor & 0.27 & & \\
\hline ACVR1 & Activin type I receptor & 0.30 & & \\
\hline ADRB2 & Adrenergic, beta-2- receptor & 0.32 & & 0.49 \\
\hline IFNGR2 & Interferon gamma receptor 2 & 0.27 & & \\
\hline FOLR2 & Folate receptor 2 & 0.47 & & 0.44 \\
\hline ADIPOR1 & Adiponectin receptor 1 & 0.48 & & \\
\hline
\end{tabular}

${ }^{\mathrm{a}}$ Genes shown in boldface were used in qPCR verification

${ }^{b}$ Only the fold change of differentially expressed genes related to energy metabolism, muscle structure, and stress response are shown. Values $>1.0$ show upregulation, and $<1.0$ show downregulation

0040010), glucose metabolism (GO:0006006, GO: 0006096, GO:0006007), and catabolic process (GO: 0009056, GO:0044282); the upregulated genes are involved in immune or heat stress response (GO:0006955, GO:0009408), negative regulation of cell cycle (GO: 0045786), response to DNA damage stimulus or DNA recombination (GO:0006974, GO:0006310), negative regulation of catalytic activity (GO:0043086), and protein folding (GO:0006457) (Additional file 4: Table S4).

To define the biological pathways potentially associated with heat stress on meat quality or growth performance, KEGG pathway analysis (Table 3) revealed that, compared with the 22AL controls, the significantly upregulated pathways in 35AL were associated with ribosomes, p53 signaling pathway, and adipocytokine signaling pathway, whereas downregulated pathways were related to arginine and proline metabolism, glycolysis/gluconeogenesis, PPAR signaling, phagosome, and endocytosis pathways, citrate cycle (TCA cycle), dilated cardiomyopathy pathway, fatty acid metabolism, valine, leucine and isoleucine degradation, pyruvate metabolism, and leukocyte transendothelial migration pathway. Compared with the 22AL controls, metabolism of xenobiotics by cytochrome P450, bile secretion, and PPAR signaling pathway were upregulated in 22PF pigs and dilated cardiomyopathy, phagosome and antigen processing, and presentation were downregulated. 
Table 3 Significant KEGG pathway analysis

\begin{tabular}{|c|c|c|c|c|c|}
\hline \multicolumn{2}{|c|}{ Pathway name } & Gene involved & $p$ & FDR & Genes \\
\hline \multicolumn{6}{|c|}{ 22PF vs 22AL (up) } \\
\hline \multirow[t]{3}{*}{ Up } & $\begin{array}{l}\text { Metabolism of } \\
\text { xenobiotics by } \\
\text { cytochrome P450 }\end{array}$ & $2 / 53$ & 0.0110 & 0.782 & CYP2E1//SULT2A1 \\
\hline & Bile secretion & $2 / 59$ & 0.0136 & 0.782 & OCT1//SULT2A1 \\
\hline & PPAR signaling pathway & $2 / 64$ & 0.0158 & 0.782 & APOC3//PCK1 \\
\hline \multirow[t]{3}{*}{ Down } & Dilated cardiomyopathy & $5 / 41$ & 0.0003 & 0.0483 & ACTC1//MLC2VI/PLN//TNNI3//TPM3 \\
\hline & Phagosome & $6 / 134$ & 0.0003 & 0.0483 & GP91-PHOX//SLA-5//SLA-DQA1//SLA-DRB1//THBS1//THBS3 \\
\hline & $\begin{array}{l}\text { Antigen processing and } \\
\text { presentation }\end{array}$ & $4 / 63$ & 0.0011 & 0.054 & CD8A//SLA-5//SLA-DQA1//SLA-DRB1 \\
\hline \multicolumn{6}{|c|}{$35 \mathrm{AL}$ vs $22 \mathrm{AL}$} \\
\hline \multirow[t]{3}{*}{ Up } & Ribosome & $6 / 83$ & 0.0008 & 0.13 & RPL10A//RPL11//RPL14//RPLP1//RPS17//RPS4 \\
\hline & p53 signaling pathway & $5 / 60$ & 0.0011 & 0.13 & BID//CDKN1A//FAS//GADD45A//IGF1 \\
\hline & $\begin{array}{l}\text { Adipocytokine signaling } \\
\text { pathway }\end{array}$ & $3 / 61$ & 0.0468 & 1 & PCK1//POMC//PPARGC-1 \\
\hline \multirow[t]{11}{*}{ Down } & $\begin{array}{l}\text { Arginine and proline } \\
\text { metabolism }\end{array}$ & $11 / 47$ & 3.09E-07 & $7.64 \mathrm{E}-05$ & ACY1//ALDH2//ARG2//CKM//CKMT2//GATM//GLUD1//GLUL//GOT1//GOT2//P4HA1 \\
\hline & $\begin{array}{l}\text { Glycolysis/ } \\
\text { gluconeogenesis }\end{array}$ & $9 / 51$ & 4.38E-05 & 0.0024 & ACSS2//ALDH2//DLAT//DLD//GPI//PFKM//PGM1//PKM2//TPI1 \\
\hline & PPAR signaling pathway & $10 / 64$ & 4.92E-05 & 0.0024 & ACADL//ACADM//ACOX1//ACSL1//CD36//CPT1B//CYP27A1//FABP3//LPL//SCD \\
\hline & Phagosome & $14 / 134$ & 0.0002 & 0.0056 & $\begin{array}{l}\text { ACTB//ACTB//ATP6V1D//ATP6V1G1//CD36//EEA1//ITGAVI/ITGB1//M6PR//SLA-1// } \\
\text { SLA-3//SLA-5//SLA-DQA1//SLA-DRB1 }\end{array}$ \\
\hline & Endocytosis & $16 / 179$ & 0.0003 & 0.0081 & $\begin{array}{l}\text { ADRB2//CAV1//CAV2//CXCR4//EEA1//EGF//EPS15//FOLR2//MDM2//MET//SLA-1// } \\
\text { SLA-3//SLA-5//TGFB2//USP8//WWP1 }\end{array}$ \\
\hline & Citrate cycle (TCA cycle) & $6 / 29$ & 0.0004 & 0.0081 & DLAT//DLD//FH//IDH2//IDH3A//SDHA \\
\hline & Dilated cardiomyopathy & $10 / 81$ & 0.0004 & 0.0081 & ACTB//ACTB//ACTC1//DES//ITGAV//ITGB1//LMNA//SGCA//TGFB2//TPM2 \\
\hline & Fatty acid metabolism & $7 / 41$ & 0.0004 & 0.0081 & ACADL//ACADM//ACOX1//ACSL1//ALDH2//CPT1B//LCTHIO \\
\hline & $\begin{array}{l}\text { Valine, leucine and } \\
\text { isoleucine degradation }\end{array}$ & $7 / 44$ & 0.0006 & 0.0117 & ACADM//ALDH2//BCKDHA//BCKDHB//DLD//LCTHIO//PCCB \\
\hline & Pyruvate metabolism & $6 / 36$ & 0.0012 & 0.0194 & ACSS2//ALDH2//DLAT//DLD//GLO1//PKM2 \\
\hline & $\begin{array}{l}\text { Leukocyte } \\
\text { transendothelial } \\
\text { migration }\end{array}$ & $10 / 103$ & 0.0024 & 0.0354 & ACTB//ACTB//CDH5//CTNNB1//CXCL12//CXCR4//F11R//ITGB1//MAPK14//RAP1A \\
\hline \multicolumn{6}{|c|}{$35 \mathrm{AL}$ vs 22PF (up) } \\
\hline \multirow[t]{3}{*}{ Up } & $\begin{array}{l}\text { Adipocytokine signaling } \\
\text { pathway }\end{array}$ & $3 / 60$ & $1.6 \mathrm{E}-06$ & 0.0004 & PCK1//POMC//PPARGC-1 \\
\hline & Herpes simplex infection & $8 / 157$ & 0.0002 & 0.0193 & CASP3//CCL5//OAS1//OAS2//PTPN11//SLA//SOCS3//STAT2 \\
\hline & $\begin{array}{l}\text { Toll-like receptor } \\
\text { signaling pathway }\end{array}$ & $6 / 87$ & 0.0002 & 0.0193 & CCL5//CD40//CXCL10//MAPK14//TICAM2//TLR1 \\
\hline \multirow[t]{7}{*}{ Down } & $\begin{array}{l}\text { Glycolysis/ } \\
\text { gluconeogenesis }\end{array}$ & $7 / 51$ & 1.97E-05 & 0.0049 & DLD//ENO3//GPI//PFKM//PGM1//PKM2//TPI1 \\
\hline & Citrate cycle (TCA cycle) & $5 / 29$ & 0.0001 & 0.0131 & $D L D / / F H / / I D H 2 / / I D H 3 A / / M D H 2$ \\
\hline & $\begin{array}{l}\text { Hypertrophic } \\
\text { cardiomyopathy (HCM) }\end{array}$ & $7 / 76$ & 0.0003 & 0.0166 & CACNA2D1//DES//ITGB1//LMNA//SGCA//TGFB3//TPM2 \\
\hline & $\begin{array}{l}\text { Starch and sucrose } \\
\text { metabolism }\end{array}$ & $5 / 35$ & 0.0003 & 0.0166 & AMY2//GPI//PGM1//PYGM//UGP2 \\
\hline & Dilated cardiomyopathy & $7 / 81$ & 0.0004 & 0.0194 & CACNA2D1//DES//ITGB1//LMNA//SGCA//TGFB3//TPM2 \\
\hline & $\begin{array}{l}\text { Arginine and proline } \\
\text { metabolism }\end{array}$ & $5 / 47$ & 0.0011 & 0.0381 & ACY1//CKM//GLUD1//GOT1//MAOB \\
\hline & PPAR signaling pathway & $4 / 64$ & 0.022 & 1.6496 & ACADM//ACSL1//APOC3//CYP27A1 \\
\hline
\end{tabular}


The comparison between 35AL and 22PF groups of pigs identified direct effects of heat treatment, showing upregulation of adipocytokine signaling pathway, Herpes simplex infection, and Toll-like receptor signaling pathway, and downregulation of glycolysis/gluconeogenesis, citrate cycle (TCA cycle), hypertrophic cardiomyopathy (HCM), starch and sucrose metabolism, dilated cardiomyopathy, arginine, and proline metabolism pathways.

\section{Verification of mRNA array analyses with qPCR}

A selection of 14 genes with relatively large change and related to muscular energy metabolism or muscle development, DECR1, FABP3, GHR, HSPA1L, LPIN1, LPL, MB, MSTN, PFKM, PPARGC1, TNNI1, TNNT3, FASN, and PCK1 (see Table 2), were chosen to verify that their relative transcript abundance determined by the genechips could be confirmed by real-time PCR (qPCR). With the exception of PPARGC1, there were high correlations between the two methods (Fig. 2).

Based on these results, 11 proteins (DECR1, FABP3, HSPAL1, LPIN1, PFKM, TNNT3, TNNI1, PPARGC-1, MSTN, FASN, and PCK1) were selected and correspondence between protein abundance, by Western blots, and transcript abundance, by qPCR, was examined. The results (Fig. 3) showed that the relative transcript abundance of 13 genes (DECR1, FABP3, GHR, HSPA1L, LPIN1, LPL, MB, MSTN, PFKM, TNNT1, TNNT3, FASN, and $P C K 1$ ) had high correlations to the mRNA array result. While PPARGC1 had lower correlations to the mRNA array result. Among 11 proteins, the DECR, FABP3, LPINI, and TNNT1protein levels were downregulated and PCK1 protein level was upregulated in 35AL and 22PF group compared with the control, which were correspondent with their mRNA result, but TNNT3, MSTN, and FASN protein levels in 35AL group and 22PF group were not different from that in the 22AL group, which were not correspondent with their mRNA result. HSPAL1 protein level was upregulated and PFKM was downregulated in 35AL compared with 22PF and 22AL group, which were correspondent with their mRNA result. Both PPARGC-1 protein level and mRNA level in 35AL group were downregulated, which is not consistent with the mRNA array result (Table 4).

\section{Discussion}

The present study showed that high temperature decreased the growth performance, which is consistent with others' findings [1-3]. Le Dividich et al. [6] reported that high temperature decreased feed intake and that decreased energy intake was the main reason for the decreased IMF deposition. The restricted feed intake from exposure here to high temperature also decreased IMF content, indicating that the effect of high temperature on IMF content was explained mainly by the decreased feed intake. In addition, many genes related with lipid metabolism such as FABP3, LPL, SCD, DECR, and LPINI were downregulated, which decreased the fat synthesis and deposition. High temperature also increased $\mathrm{pH}$ value and decreased the content of glycogen in muscle, which is consistent with $\mathrm{Hu}$ et al. [15]. The shear force in feed-restricted group is greater compared to the control group, because of the lower intramuscular fat. As high temperature decreased the calpastatin expression [16] and possibly enhancing postmortem proteolysis to offset any decreased tenderness from the lower IMF content, the shear force in higher temperature is not different from the control.

In this study, mRNA array analysis of the LM was used to explore the mechanisms of underlying the effects of high temperature on meat quality and growth performance. High temperature has previously been shown to cause DNA damage $[16,17]$ and protein misfolding [18], heat stress increased the expression of heat shock proteins, especially the heat shock protein 70 family $[19,20]$. In the present study, the GO analysis showed that high temperature per se upregulated gene expression involved in stress reaction in cells, including GTF2H4, ERCC1, HSPA1L, POLL, mutL homolog 1 (MLH1), GADD45A, and CDKN1A. HSPAL1 belong to 70-kDa heat shock proteins (Hsp70s), which have housekeeping functions and assist a wide range of folding processes, including the folding and assembly of newly synthesized proteins, refolding of mis-folded and aggregated proteins, membrane translocation of cellular and secretory proteins, and control of the activity of regulatory proteins $[21,22]$. In addition, heat shock proteins also adjust redox balance and relieve oxidative stress through inhibiting the activity of NADPH oxidase [23], which was one of the important reasons for high temperature causing oxidative stress. Compared with the 22PF pigs, the 35AL animals had increased expression of heat shock protein $90(H S P C B)$, heat shock protein 90 (HSPH1). The GTF2H4 and ERCC1 genes also are involved in DNA repair-related biological processes, reflecting an enhanced self-protecting mechanism under high temperature stress. In addition, genes of ncRNA and rRNA metabolism, protein translation, and translation extension also were upregulated, which might be required by synthesis of heat stress proteins.

Heat stress also affected expression of some genes related to muscle structure. Many studies have reported that high temperature decreased carcass muscle weight $[2,24,25]$. High temperature here decreased the relative expression of actin protein genes in LM including ACTA2, ACTC1, and ACTA1, myosin heavy chain IIb (MYH4), myofibrillar protein connection (DES), the connection protein with the membrane and myofibrils (SGCA), troponinsTNNT3 andTNNI1, nest bridge 


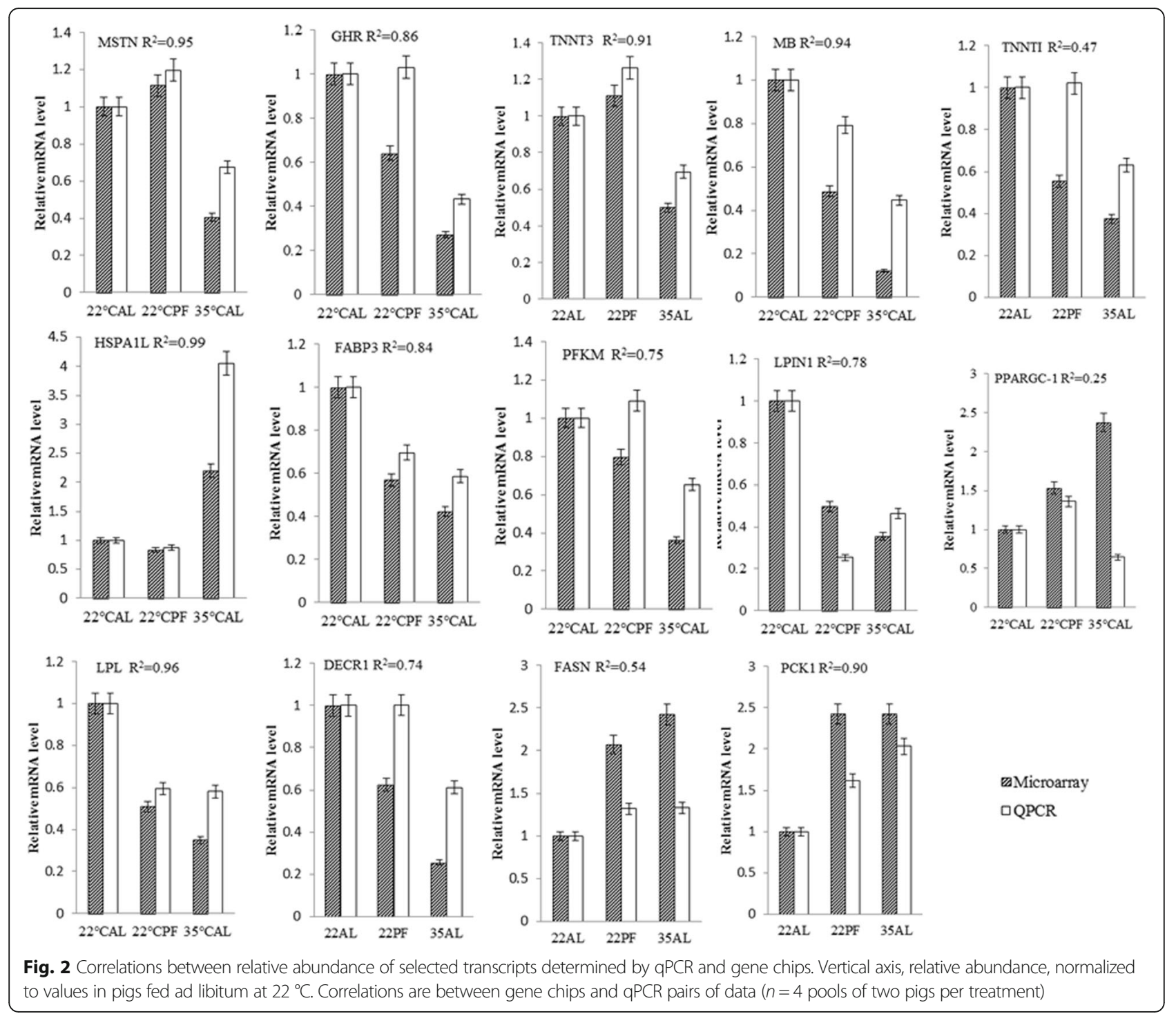

proteins $(C A V 2,3), \beta$-Tropomyosin (TPM2), and Integri$\mathrm{n} \beta 1(I T G B 1)$, all involved in muscle structure, fiber development, or muscle contraction. In addition, the hightemperature treatment induced a fiber transformation from slow type to fast type and downregulated CaMK and PPAR signaling pathways, but limited feed intake did not. The change in fiber type is largely caused by reduced CaMK and PPAR cell signaling. For example, Gibala et al. [26] reported that over-expression of PPAR$\gamma$ induced a cell transformation from type II to type I. High temperature decreased muscle development here, independently of the reduced feed intake.

High temperature also affected expression of the genes related to energy metabolism. Rinaldo and Le Dividich [7] previously reported that high temperature decreased key enzymes related to oxidative and glycolytic metabolisms including lactate dehydrogenase, betahydroxy coenzyme A dehydrogenase, citrate synthase, and cytochrome oxidase. Weller et al [10] then reported that high temperature $\left(34{ }^{\circ} \mathrm{C}\right)$ decreased gene expression of NADH dehydrogenase 1 (ND1), NADH dehydrogenase 2 (ND2), cytochrome C oxidase complex, ATP5, ATP6, and others involved in the electron transport chain. These results implied that long-term exposure to high temperature reduced the level of energy metabolism in muscle. Consistent with those findings, high temperature here decreased expression of phosphofructokinase (PFKM), glucose-6-phosphate isomerase (GPI), pyruvate kinase (PKM2), triosephosphateisomerase 1 (TPI1), isocitrate dehydrogenase 3 (IDH3A), and others involved in carbohydrate metabolism, glucose metabolism, and other biological processes. Downregulated expression of these genes indicated that the g glycolytic and oxidative metabolisms were decreased under high temperature environment, and this would be expected to affect meat quality. 


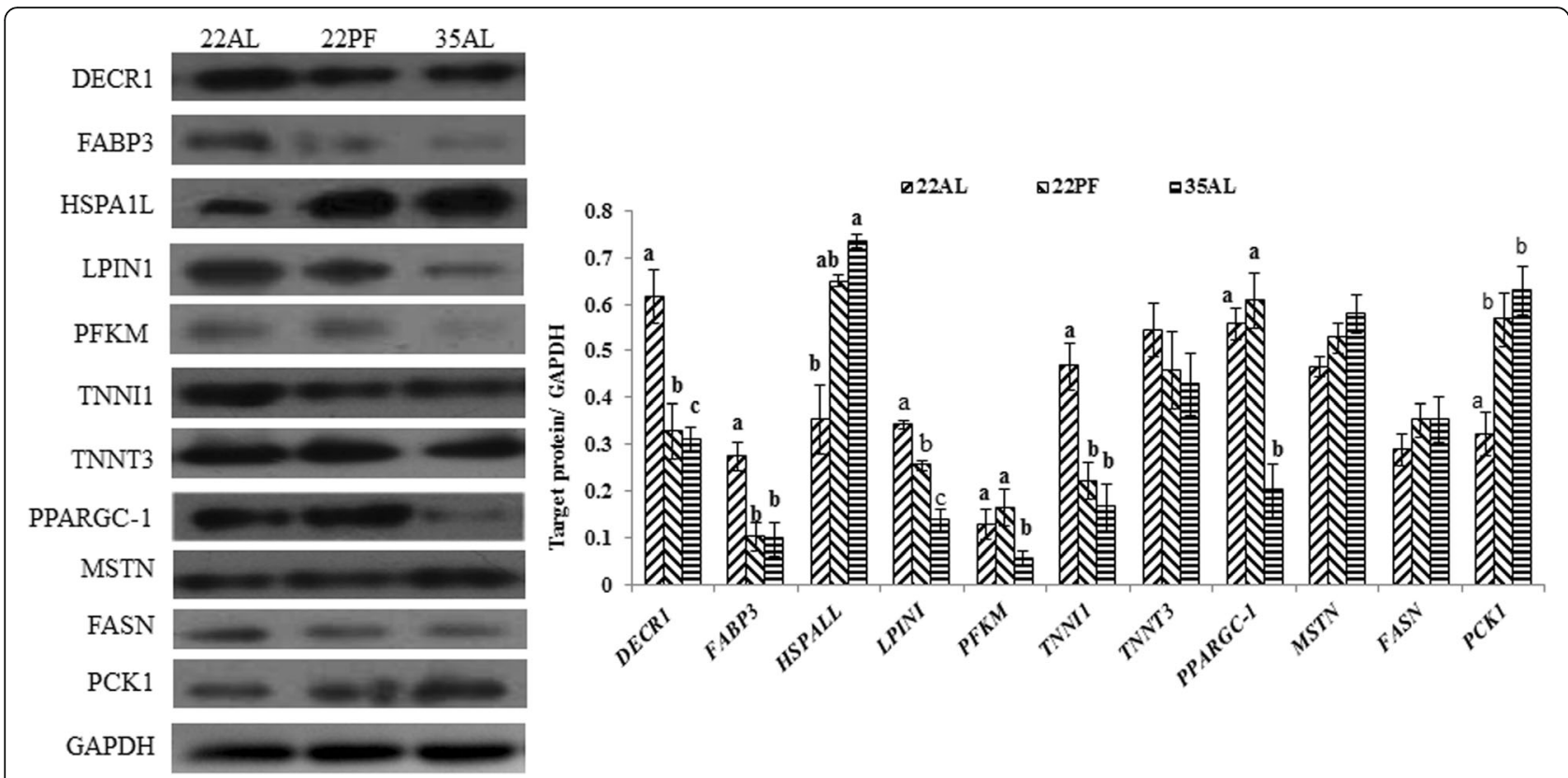

Fig. 3 Western blots for a selection of differentially expressed proteins. Targeted protein DECR1, FABP3, HSPA1L, LPIN1, PFKM, TNNT3, TNNI1, PPARGC1, MSTN, FASN, and PCK1, with GAPDH as a reference protein. a Representative sample from each treatment fractionated by SDS-PAGE, blotted and then detected with specific antibodies. $\mathbf{b}$ Semi-quantification of protein content from scans of band, ( $n=4$ pools of two pigs per treatment)

High temperature also downregulated genes involved in the TCA cycle, likely indicating reduced total energy metabolism in muscle. It also reduced expression of genes involved in ATP and amino acid synthesis and decomposition. These changes likely provide an adaptive, reduced thermogenic response to heat stress. In the amino acid synthesis and decomposition category, aspartate amino-transferase (GOT) and creatine kinase (CKM) both relate to intramuscular energy, creatine, and ADP phosphoexchange, and therefore generation of hydrogen ions determining postmortem $\mathrm{pH}$ [27]. Kwasiborski et al. [28] reported that high levels of CKM in muscle lead to an increase in the rate of muscle metabolism within the early stages after slaughter, so that ultimate $\mathrm{pH}$ is lower. High temperature here decreased the CKM expression, which may be a reason for the higher $\mathrm{pH}$. Related to decrease the content of IMF, high temperature altered expression of genes involved in lipid metabolism. For example, catalytic subunit A ( $P P P 3 C B)$, signal transducer and activator of transcription $5 \mathrm{~A}$ (STAT5A), and ATP5B synthase beta subunit (ATP) were downregulated in animals exposed to high temperature, as were fatty acid binding protein 3 (FABP3), long-chain acyl coenzyme A dehydrogenase (ACADL), mediumchain acyl coenzyme A dehydrogenase $(A C A D M)$, palmitoyl coenzyme A oxidase (ACOX1), Ketoacyl CoA Thiolase $(L C T H I O)$, and carnitine acyl transfer enzyme $1 \mathrm{~B}$ $(C P T 1 B)$, involved in fatty acid location and beta oxidation-related processes. A decline in oxidative capacity may be another adaptation to high temperature by reducing thermogenesis. Wu et al. [29] found that high temperature decreased IMF content by decreasing the activities of acetyl coenzyme A (ACC) and fatty acid synthase (FAS); it also inhibited beta-oxidation of fatty acids by decreasing the hydroxyacyl CoA dehydrogenase (HAD) in skeletal muscle. FASN, involved in fatty acid synthesis, was upregulated in mRNA array data, but qPCR and Western-blot in this present research showed that there were no differences on FASN protein among three groups, probably the fatty acid synthesis try to compensate for too lower IMF.

In the 22PF animals, the effects of reduced intake were separated from heat-stress per se; genes involved in fatty acid decomposition including DECR1, LPIN1, FABP3, and CPT1A were downregulated; the GO analysis result showed that muscle cell development and cellular component biogenesis also were downregulated. Some genes related to lipid metabolite such apolipoprotein $\mathrm{C} 3$ (APOC3), cytochrome P4502C34 (CYP2C34), P450 2E1 (CYP2E1), sulfate transferase 2A1 (SULT2A1), phosphatidylserine decarboxylase proenzyme (PISD), serum retinol binding protein 4 (RBP4), and PEP carboxykinase1 (PCK1) were not influenced by restricted feed intake. $\mathrm{Al}$ though response to nutrient levels, vitamins and proteins, and lipid metabolic process were upregulated, the growth performance and IMF were lower than in 22AL group, which implies that the nutrient or energy intake did not meet the need of the pigs, and the pigs try to synthesize fat or other nutrients, but the nutrient and energy were too low to satisfy the needs of the pigs. 
Table 4 Primer sequences

\begin{tabular}{|c|c|c|c|}
\hline Target gene & Primer sequence ( $5^{\prime}$ to $\left.3^{\prime}\right)$ & Accession no. & Product size (bp) \\
\hline \multirow[t]{2}{*}{ FABP3 } & Forward: CGCCTGTTCTGTCGTCTC & NM_001099931.1 & 263 \\
\hline & Reverse: TCTCATCAAACTCCACTCCC & & \\
\hline \multirow[t]{2}{*}{ GHR } & Forward: TGCCCAGGTAAGCGACAT & NM_214254.2 & 272 \\
\hline & Reverse: TGCCAGCAGTAGTGGTAAGG & & \\
\hline \multirow[t]{2}{*}{ HSPATL } & Forward: CCATGAATCCCCAGAACACT & NM_001123128.1 & 313 \\
\hline & Reverse: ATGACGCCTGCATCCTTGGT & & \\
\hline \multirow[t]{2}{*}{ Lpin 1} & Forward: TTCTCACAACACTGACCCTCTT & EU164847 & 330 \\
\hline & Reverse: GCCCTCCGACTCTAACCAC & & \\
\hline \multirow[t]{2}{*}{$M B$} & Forward: CCCGAGACCCTGGAGAAAT & NM_214236.1 & 457 \\
\hline & Reverse: CAACACTCAGAAGCAAACCCTAC & & \\
\hline \multirow[t]{2}{*}{ MSTN } & Forward: AATGAGAACAGCGAGCAA & AY448008.2 & 279 \\
\hline & Reverse: TTCCGTCGTAGCGTGATA & & \\
\hline \multirow[t]{2}{*}{ PFKM } & Forward: ACCGAGTGCTGGTTGTGC & NM_001044550.1 & 305 \\
\hline & Reverse: GTTGTTGGAGACCGTGGC & & \\
\hline \multirow[t]{2}{*}{ PPARGC-1 } & Forward: AAAGCCAACCAAGATAACCC & NM_213963.1 & 242 \\
\hline & Reverse: TCACCAAATAGCCGCAGAC & & \\
\hline \multirow[t]{2}{*}{$L P L$} & Forward: CGACTGGATGGCGGTTG & NM_214286 & 271 \\
\hline & Reverse: ATGCCCTACTGGTTTCTGGAT & & \\
\hline \multirow[t]{2}{*}{ TNNT3 } & Forward: CCCTCATCGACAGCCACTT & NM_001001863.1 & 318 \\
\hline & Reverse: GCACCTTCTTCTTCATCTCCC & & \\
\hline \multirow[t]{2}{*}{ TNNI1 } & Forward: TGAACGACCTCCAGAAAGC & NM_213912.3 & 345 \\
\hline & Reverse: GGCGGACACTCAGGAATAA & & \\
\hline \multirow[t]{2}{*}{ DECR1 } & Forward: TAAAGCACAGAAAGGAGCAG & NM_001190232.2 & 217 \\
\hline & Reverse: TCCAGTTGGGTCAAGACG & & \\
\hline \multirow[t]{2}{*}{ FASN } & Forward: CCTCATCGGCGGTGTGGA & NM_004104 & 122 \\
\hline & Reverse: TGAAGTCGAAGAAGAAGGAGAGC & & \\
\hline \multirow[t]{2}{*}{ PCK1 } & Forward: ACAGCCTGCCCCAGGC & NM_001123158 & 148 \\
\hline & Reverse: TTCAGCCTCTTGATGAC & & \\
\hline \multirow[t]{2}{*}{ 18S RNA } & Forward: GAGCGAAAGCATTTGCCAAG & AF102857 & 101 \\
\hline & Reverse: GGCATCGTTTATGGTCGGAAC & & \\
\hline
\end{tabular}

While APOC3, CYP2E1, SULT2A, and PISD were downregulated in animals exposed to high temperature and GO analysis showed that heat stress, DNA damage, and negative regulation of cell cycle were upregulated, this implied that high temperature damaged the cell function and cannot synthesize the nutrients; pigs in 35AL group did not response to the nutrient level, but did response to the heat stress. This finding clearly shows differences between high temperature and limited feed intake in their effects on transcripts related to energy metabolism in muscle.

The most imported signaling pathways, identified by KEGG, are discussed below.

\section{p53 signaling pathway}

Skeletal muscle atrophy is reflected in the number of nuclei [30], reduced mainly through apoptosis and the p53 signaling pathway, activated by stress signals including DNA damage, oxidative stress, and induction and activation of cancer genes. The p53 protein regulates transcriptional activation of many genes, mainly involved in cell cycle arrest, cell senescence, and apoptosis [31]. Nitta et al. [32] reported that high temperature arrested cell cycles depending upon the p53 signaling pathway. Exposure of pigs to high temperature in the present study increased expression of genes of the p53 signaling pathway, apoptosis, and skeletal muscle atrophy, but p53 signal pathway was just upregulated in 35ALgroup compared with 22AL and 22PFgroup, which implied that the upregulation of p53 signal pathway was a direct temperature effect. Genes such as $p 21$ (CDKN1A), Bid and FasFADD, Caspase 8, and Caspase10 were involved and are known to induce apoptosis [33]. Signaling 


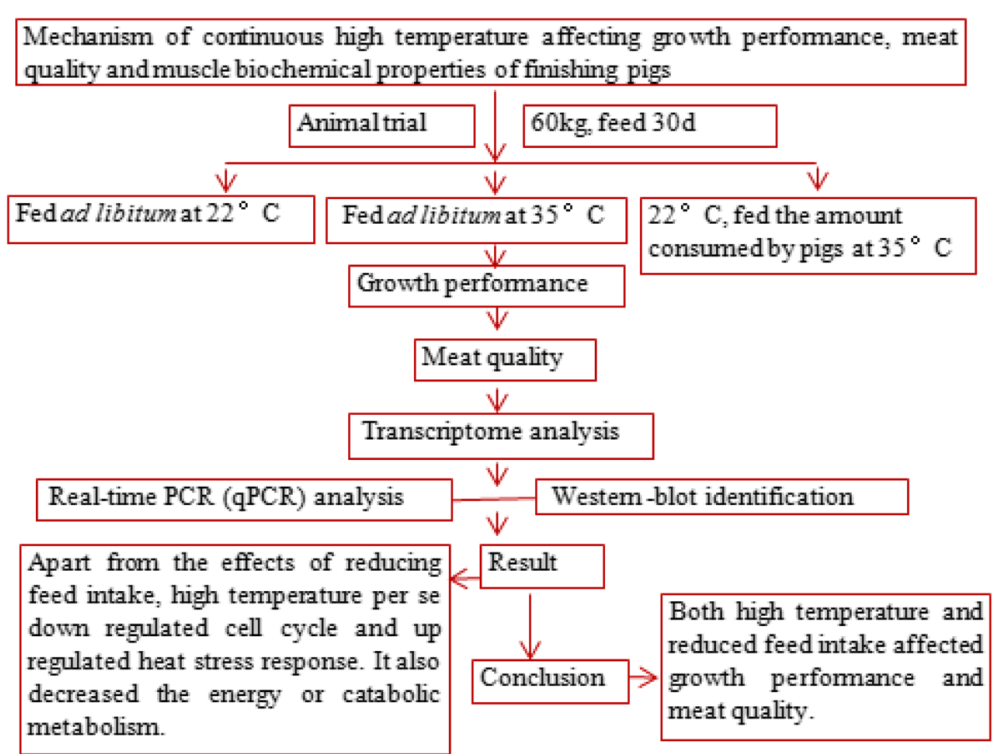

Fig. 4 TOC graphic of this article

complexes, including FADD, Caspase 8, andCaspase10, also induced apoptosis [33]. Yamada et al. [34] reported that human fast muscle type may be more likely to be induced to apoptosis and the same is true for rat [35]. So it can be deduced that high temperature induced more fast muscle type production through up-regulating the p53 pathway.

\section{PPAR signaling pathway}

PPAR-alpha and PPAR-sigma, members of the nuclear hormone receptor super family [36], influence gene transcription of fatty acid oxidation enzymes, such as $F A B P 3$, $C P T 1$, and $A B C A 1$ in skeletal muscle [37-39]. In this present study, genes of the PPAR signal pathway were downregulated in pigs exposed to high temperature, as were $A C A D L, A C A D M, A C O X 1, A C S L 1$, and $C P T 1 B$, all related to fatty acid beta-oxidation. It also is downregulated in 35AL compared with $22 \mathrm{PF}$, but the FDR is very high $(\mathrm{FDR}=1.64)$, the FDR of PPAR signaling pathway in $22 \mathrm{PF}$ vs $22 \mathrm{AL}$ also is very high $(\mathrm{FDR}=0.78)$. It was deduced, therefore, that high temperature decreased energy metabolism through the PPAR signaling pathway.

\section{Adiponectin signal pathway}

Adiponectin is an adipocytokine playing an important role in insulin sensitivity and glucose and lipid metabolism, especially in skeletal muscle; it activates AMPK, p38MAPK, and PPAR signal pathway [40] and affects fatty acid metabolism. Adipocytokine signaling pathway also was involved in adaptive responses to heat stress [19], which is important regulators of energy homeostasis, food intake, and insulin action. In the present research, adiponectin signaling pathway was downregulated in muscle of pigs exposed to high temperature, which improved energy expenditure as adaptive response to heat stress.

Combining the results of GO and KEGG pathway analyses, the genes downregulated by reduced feed intake were mainly involved in muscle contraction, muscle development, muscle system process, or differentiation, while the upregulated genes were mainly involved in response to nutrient levels or extracellular stimuli. Downregulated genes caused by high temperature were mainly involved in muscle structure and development, energy, or catabolic metabolism, while upregulated genes were mainly involved in DNA or protein damage or recombination, or processes of cell cycle, biogenesis, and stress and immune responses. The comprehensive analyses of the transcriptome of porcine skeletal muscle provided here indicate some of the molecular basis for direct effects of exposure to high temperature on traits related to meat quality, distinct from indirect effects resulting from depressed feed intake.

\section{Conclusions}

Both high temperature and reduced feed intake affected growth performance and meat quality. Apart from the effects of reducing feed intake, a direct effect of high temperature on growth performance and meat quality also was involved in negatively regulating cell cycle, stimulating protein, DNA damage and cell apoptosis, and heat stress response. High temperature also decreased the energy or catabolic metabolism level through PPAR signaling pathway (Fig. 4). 


\section{Additional files}

Additional file 1: Table S1. Ingredient 7 composition and nutrient content of the basal diets (DOCX $14 \mathrm{~kb}$ )

Additional file 2: Table S2. Go analysis of differently expressed genes in $35 \mathrm{AL}$ group compared with 22AL group (DOCX $15 \mathrm{~kb}$ )

Additional file 3: Table S3. GO analysis of differently expressed genes in 22PF group compared with 22AL group (DOCX $15 \mathrm{~kb}$ )

Additional file 4: Table S4. GO analysis of differently expressed genes in $35 \mathrm{AL}$ group compared with 22PF group (DOCX $15 \mathrm{~kb}$ )

\section{Abbreviations}

ADFl: Average daily feed intake; ADG: Average daily gain; AL: Ad libitum; BW: Body weight; F:G: Feed to gain; HCM: Hypertrophic cardiomyopathy; IMF: Intramuscular fat; LM: Longissimus muscle; PF: Pair fed; PPAR: Peroxisome proliferator activated receptor; RT: Room temperature

\section{Acknowledgements}

We thank all authors who participated in this work. We thank W. Bruce Currie (Emeritus Professor, Cornell University) for helping us edit the manuscript.

\section{Funding}

This work was supported by grants from Key project of Natural Science Foundation of Guangdong Province (2014A030311010), National Key Research and Development Program of China (2016YFD0500501, 2016YFD0501210), and the earmarked fund for Modern Agro-industry Technology Research System (2017LM1080, 2018LM1080). The National '973' Project of China (2012CB124706-5 and 4).

\section{Availability of data and materials}

If any reader needs the data, please contact the author for data requests.

\section{Authors' contributions}

XM carried out the meat quality studies, participated in the sample collection, and drafted the manuscript. LW carried out the Western-blot experiment. ZS participated to the whole experiment, WC carried out the mRNA analysis, WC carried out the mRNA analysis, XY carried out the RNA extraction, $\mathrm{YH}$ participated in the design of the study, CZ participated to the data analysis, and ZJ was in charge of experiment design and participate editing the article. All authors read and approved the final manuscript.

\section{Ethics approval and consent to participate}

All aspects of the experiment including transport and slaughtering procedures were carried out in accordance with the Chinese guidelines for the use of experimental animals and animal welfare and approved by the Animal Experimental Committee of the Institute of Animal Science, Guangdong Academy of Agricultural Sciences. Please see reference 11.

\section{Consent for publication}

All authors consent to participate and publish this article.

\section{Competing interests}

The authors declare that they have no competing interests.

\section{Author details}

'Institute of Animal Science, Guangdong Academy of Agricultural Sciences, Guangzhou 510640, People's Republic of China. ${ }^{2}$ The Key Laboratory of Animal Nutrition and Feed Science (South China) of Ministry of Agriculture, Guangzhou, China. ${ }^{3}$ State Key Laboratory of Livestock and Poultry Breeding, Guangzhou, China. ${ }^{4}$ Guangdong Key Laboratory of Animal Breeding and Nutrition, Guangzhou, China. ${ }^{5}$ Guangdong Engineering Technology Research Center of animal Meat quality and Safety Control and Evaluation, Guangzhou 510640, China.
Received: 18 January 2019 Accepted: 14 May 2019

Published online: 24 July 2019

\section{References}

1. Le Bellego L, Van Milgen J, Noblet J. Effect of high temperature and lowprotein diets on the performance of growing-finishing pigs. J Anim Sci. 2002:80:691-701.

2. Collin A, van Milgen J, Dubois S, Noblet J. Effect of high temperature and feeding level on energy utilization in piglets. J Anim Sci. 2001;79(7):1849-57.

3. Lefaucheur L, Le Dividich J, Mourot J, Monin G, Ecolan P, Krauss D. Influence of environmental temperature on growth, muscle and adipose tissue metabolism, and meat quality in swine. J Anim Sci. 1991;69:2844-54.

4. Witte DP, Ellis M, McKeith FK, Wilson ER. Effect of dietary lysine level and environmental temperature during the finishing phase on the intramuscular fat content of pork. J Anim Sci. 2000;78:1272-6.

5. Čandek-Potokar M, Žlender B, Lefaucheur L, Bonneau M. Effects of age and/ or weight at slaughter on longissimus dorsi muscle: biochemical traits and sensory quality in pigs. Meat Sci. 1998:48:287-300.

6. Le Dividich J, Noblet J, Herpin P, Van Milgen J, Quiniou N. Thermoregulation. In: Progress in pig science; 1998. p. 229-63.

7. Rinaldo D, Le Dividich J. Effects of warm exposure on adipose tissue and muscle metabolism in growing pigs. Comp Biochem Physiol A Physiol. 1991;100(4):995-1002.

8. Bernabucci U, Lacetera N, Danieli PP, Bani P, Nardone A, Ronchi B. Influence of different periods of exposure to hot environment on rumen function and diet digestibility in sheep. Int J Biometeorol. 2009:53(5):387-95.

9. Gabler NK, Pearce SC. The impact of heat stress on intestinal function and productivity in grow-finish pigs. Animal production Science. 2015:55(12): 1403-10.

10. Weller MM, Alebrante L, Campos PH, Saraiva A, Silva BA, Donzele JL, et al. Effect of heat stress and feeding phosphorus levels on pig electron transport chain gene expression. Animal. 2013;7(12):1985-93.

11. Science and Technology Ministry of China, The guiding suggestion about treating experimental animals amicably. 2006, Document no. 398

12. Mason LM, Hogan SA, Lynch A, O'Sullivan K, Lawlor PG, Kerry JP. Effect of restricted feeding and antioxidant supplementation on pig performance and quality characteristics of longissimusdorsi muscle from Landrace and Duroc pigs. Meat Sci. 2005;70:307-17.

13. AOAC Fat (crude) in meat and meat products (16th method 991.36). Arlington: Association of Official Analytical Chemists; 1995.

14. Ma XY, Lin YC, Jiang ZY, Zheng $C T$, Zhou GL. Dietary arginine supplementation enhances antioxidant capacity and improves meat quality of finishing pigs. Amino Acids. 2010;38:95-102.

15. Hu H, Bai X, Shah AA, Dai S, Wang L, Hua J, et al. Interactive effects of glutamine and gamma-aminobutyric acid on growth performance and skeletal muscle amino acid metabolism of 22-42-day-old broilers exposed to hot environment. Int J Biometeorol. 2016;60(6):907-15.

16. Paul C, Murray AA, Spears N, Saunders PT. A single, mild, transient scrotal heat stress causes DNA damage, subfertility and impairs formation of blastocysts in mice. Reproduction. 2008;136(1):73-84

17. Bruskov VI, Malakhova LV, Masalimov ZK, Chernikov AV. Heat-induced formation of reactive oxygen species and 8-oxoguanine, a biomarker of damage to DNA. Nucleic Acids Res. 2002;30(6):1354-63.

18. Rotiroti JL. Cellular responses to hyperthermia (40-46 degrees C): cell killing and molecular events. Int J Hyperth. 2008;24(1):3-15.

19. Morera P, Basiricò L, Hosoda K, Bernabucci U. Chronic heat stress upregulates leptin and adiponectin secretion and expression and improves leptin, adiponectin and insulin sensitivity in mice. J Mol Endocrinol. 2012; 48(2):129-38.

20. Lewis MJ, Pelham HR. Involvement of ATP in the nuclear and nucleolar functions of the $70 \mathrm{kd}$ heat shock protein. EMBO J. 1985:4(12):3137-43.

21. Mayer MP, Bukau B. Hsp70 chaperones: cellular functions and molecular mechanism. Cell Mol Life Sci. 2005:62(6):670-84.

22. Sharp FR, Massa SM, Swanson RA. Heat-shock protein protection. Trends Neurosci. 1999:22(3):97-9.

23. Martindale JL, Holbrook NJ. Cellular response to oxidative stress: signaling for suicide and survival. J Cell Physiol. 2002;192(1):1-15.

24. Close WH, Mount LE. The effects of plane of nutrition and environmental temperature on the energy metabolism of the growing pig. Br J Nutr. 1978; 40(3):413-21. 
25. Bridges TC, Turner LW, Gates RS. Economic evaluation of misting-cooling systems for growing/finishing swine through modeling. Appl Eng Agric. 1998;14(4):425-30.

26. Gibala MJ, McGee SL, Garnham AP, Howlett KF, Snow RJ, Hargreave M. Brief intense interval exercise activates AMPK and p38 MAPK signaling and increases the expression of PGC-1alpha in human skeletal muscle. J Appl Physio. 2009;106(3):929-34.

27. Bendall JR. Postmortem changes in muscle. Struct Funct Muscle. 1973;2(Part 2): 244-309.

28. Kwasiborski A, Sayd T, Chambon C, Santé-Lhoutellier V, Rocha D, Terlouw C. Pig Longissimus lumborum proteome: part II: relationships between protein content and meat quality. Meat Sci. 2008;80(4):982-96.

29. Wu X. Effects of environmental high temperature on fat metabolism in different parts of finishing pigs. Chinese Academy of Agricultural Sciences; 2014.

30. Leeuwenburgh C. Role of apoptosis in sarcopenia. J Gerontol Ser A Biol SCi Med Sci. 2003;58(11):999-1001.

31. Fridman JS, Lowe SW. Control of apoptosis by p53. Oncogene. 2003;22(56): 9030-40.

32. Nitta $\mathrm{M}, \mathrm{Okamura} \mathrm{H}$, Aizawa $\mathrm{S}$, Yamaizumi M. Heat shock induces transient p53-dependent cell cycle arrest at G1/S. Oncogene. 1997;15(5):561-8.

33. Juo P, Kuo CJ, Yuan J, Blenis J. Essential requirement for caspase-8/FLICE in the initiation of the Fas-induced apoptotic cascade. Curr Biol. 1998:8(18): $1001-8$.

34. Yamada H, Nakagawa M, Higuchi I, Ohkubo R, Osame M. Type II muscle fibers are stained by anti-Fas antibody. J Neurol Sci. 1995;134(1):115-8.

35. Libera LD, Zennaro R, Sandri M, Ambrosio GB, Vescovo G. Apoptosis and atrophy in rat slow skeletal muscles in chronic heart failure. Am J Phys. 1999;277(5Pt1):C982-6.

36. Gilde AJ, Van Bilsen M. Peroxisome proliferator-activated receptors (PPARS): regulators of gene expression in heart and skeletal muscle. Acta Physiol Scand. 2003;178(4):425-34

37. Mascaró C, Acosta E, Ortiz JA, Marrero PF, Hegardt FG, Haro D. Control of human muscle-type carnitine palmitoyltransferase I gene transcription by peroxisome proliferator-activated receptor. J Biol Chem. 1998;273(15):8560-3.

38. Krämer DK, Al-Khalili L, Guigas B, Leng Y, Garcia-Roves PM, Krook A. Role of AMP kinase and PPARS in the regulation of lipid and glucose metabolism in human skeletal muscle. J Biol Chem. 2007;282(27):19313-20.

39. Sprecher DL, Massien C, Pearce G, Billin AN, Perlstein I, Willson TM, et al. Triglyceride: high-density lipoprotein cholesterol effects in healthy subjects administered a peroxisome proliferator activated receptor delta agonist. Arterioscler Thromb Vasc Biol. 2007;27(2):359-65.

40. Yamauchi T, Kamon J, Ito Y, Tsuchida A, Yokomizo T, Kita S, et al. Cloning of adiponectin receptors that mediate antidiabetic metabolic effects. Nature. 2003:423(6941):762-9.

\section{Publisher's Note}

Springer Nature remains neutral with regard to jurisdictional claims in published maps and institutional affiliations.

Ready to submit your research? Choose BMC and benefit from:

- fast, convenient online submission

- thorough peer review by experienced researchers in your field

- rapid publication on acceptance

- support for research data, including large and complex data types

- gold Open Access which fosters wider collaboration and increased citations

- maximum visibility for your research: over $100 \mathrm{M}$ website views per year

At $\mathrm{BMC}$, research is always in progress.

Learn more biomedcentral.com/submissions 